\title{
The Effect of a Face on Packaging from the Perspective of Marketing Communication with Older Consumers
}

\author{
Ewa JERZYK, Natalia WAWRZYNKIEWICZ \\ Poznań University of Economics and Business, Poznań, Poland \\ \{ewa.jerzyk, natalia.wawrzynkiewicz\}@ue.poznan.pl
}

\begin{abstract}
The article aims at researching the response of older consumers to a face image on the packaging of food products, with an emphasis on the number of faces, their age and the viewing direction. The study is based on the findings of eye-tracking research and surveys conducted on elderly respondents. Two packages of flour were used for the research, each of which appeared in five variants: four with face images (an older and a younger woman, an old woman with a granddaughter and the whole family), as well as a control package without an image of a person. Moreover, the older consumers' visual attention and the intentionality of a purchase were analysed. It was established that products with faces on their packaging attract the older respondents' visual attention and shorten the identification time but are consciously ignored in declarative shopping. Therefore, a higher visual attention drawn to packaging with images of faces does not entail a higher purchasing preference among senior buyers. What is more, it turned out that ecological symbols and those indicating the rural nature of a product, such as the sun or ears of grain, are more valuable for the prediction of the buying decision of older consumers. The article is researchbased and conceptual
\end{abstract}

Keywords: Buying Behaviour, Older Consumer, Communication, Packaging, Face, Food.

\section{$1 \quad$ Introduction}

Through the increasing number of visual stimuli, modern marketing forces consumers to be constantly visually active. This leads to a situation in which consumers' decisions are based almost entirely on visual stimuli. People are protected against the overflow of visual information by the brain, which analyses the incoming stimuli and decides whether they should be absorbed in an automatic manner (System I), or consciously (System II) [8]. Numerous researchers hold an opinion that this process is determined by the emotional significance of a stimuli for the consumer [1]. For the majority of people, the most common emotional stimuli are faces, which have the highest ability of attracting attention, which may lead to a purchasing decision [12]. In comparison to other visual stimuli, faces are more quickly noticed, and their emotional input may affect the recipients' attitudes and purchasing motivations. Smiling faces, at an appropriate age, looking directly at the consumer, a single person or a group of people, 
determine the consumers' attitudes and buying intentions. However, consumers' reactions to images of people may vary. Research results show a different response to faces in marketing messages of younger and older consumers [4, 6]. Due to the prospectivity of the market segment of senior consumers in Poland [11], this research has been limited to this group of buyers. The interest in older consumers also resulted from the lack of research into the issue of the influence of age on the preferences for products with face images. The authors limited their study to the packaging of food products, as this category of products is most frequently bought by older consumers. The first part of the article presents the major theoretical and empirical background of the effect of a face on packaging on older consumers. The further part includes the research methodology and the findings.

\section{The Research Methodology and Findings}

The experiment was conducted in the Consumer Research Laboratory of Poznan University of Economics and Business and consisted of an eye-tracking part and a survey. 32 female respondents took part in the experiment. However, after eliminating the questionnaires with deficient data or faulty eye-tracking measures, the sample of 25 respondents remained. Owing to the small size of the sample and the way in which the respondents were selected, this research should be regarded as a starting point for further studies, rather than a comprehensive reply to the research questions. As the research was related to packets of flour, only women were invited to take part. The youngest respondent was 51 and the oldest - 77. The average age of the respondents was 61.17 respondents declared a very good health condition, 10 of them stated that their health is good, 4 women claimed to have a medium state of health and one of them declared to have poor health. The respondents were professionally active -24 of them working full-time and two - occasionally. None of them declared to be unemployed or a pensioner. Therefore, the majority of the respondents represent a relatively highincome level, which might contribute to their self-fulfilment and life satisfaction higher than the average level for this age group.

The first part of the experiment consisted in studying the parameters of respondents' visual attention. Their pupil movements, the fixation and the viewing direction were measured by means of a mobile eyetracker. It identifies the spot a person is currently looking at and enables tracking the route covered by the respondent's sight. In the first part of the study 2 packets of flour were used (in two colors: green and yellow). Each packet appeared in 5 research variants:

- a young woman's face (ca. $20-25)$,

- an older woman's face ('I'm just like you'),

- a grandmother's and a granddaughter's faces (family),

- family faces (parents and children, model $2+1$ or $2+2$ ),

- no faces. 
For one of the packets, the condition of the viewing direction was applied (faces with direct and indirect viewing). The faces used in the research were smiling, with moderate emotionality, characteristic of European culture.

In the second part of the research a survey was conducted, aiming at defining the cognitive age of the respondents and the intentional purchase of the products. The respondents were asked to select a packet of flour which most encouraged a purchase. Next, by means of the 5-degree Likert scale ( 1 - absolutely not and 5 - definitely yes), they assessed the product's quality, the aesthetic value of the packaging and its colors. They also referred to statements such as: "This product guarantees a successful cake", "This product inspires trust", "The packaging encourages buying".

The research findings analysis began with the AIO eye-tracking data, primarily based on the comparison of three values for the specific areas of the packaging (table 1):

- average total dwell time,

- average number of revisits,

- average fixation time.

Table 1. Comparison of the AIO eye-tracking indicators for the analyzed variants of packaging.

\begin{tabular}{|c|c|c|c|c|c|}
\hline $\begin{array}{l}\text { Packaging } \\
\text { colour }\end{array}$ & $\begin{array}{l}\text { Packaging } \\
\text { variant }\end{array}$ & $\begin{array}{l}\text { Packaging } \\
\text { element }\end{array}$ & $\begin{array}{l}\text { Total dwell } \\
\text { time }\end{array}$ & $\begin{array}{l}\text { Number of } \\
\text { revisits }\end{array}$ & $\begin{array}{l}\text { Average } \\
\text { fixation } \\
\text { duration }\end{array}$ \\
\hline \multirow{12}{*}{ 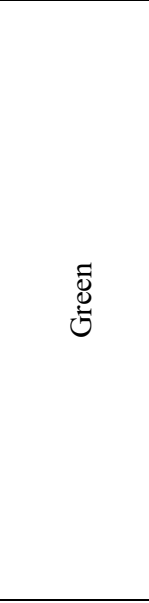 } & \multirow{3}{*}{ Young person } & Face & 1081.7 & 2.2 & 210.8 \\
\hline & & Logo & 686.3 & 1.3 & 223.7 \\
\hline & & Information & 1733.7 & 2.5 & 239.1 \\
\hline & \multirow{3}{*}{ Older person } & Face & 954.7 & 2.3 & 221.2 \\
\hline & & Logo & 923.8 & 1.7 & 242.9 \\
\hline & & Information & 2022.4 & 3.7 & 223.4 \\
\hline & \multirow{3}{*}{$\begin{array}{l}\text { Grandmother } \\
\text { with } \\
\text { granddaughter }\end{array}$} & Faces & 1552.2 & 2.3 & 243.7 \\
\hline & & Logo & 591.9 & 1.1 & 204.8 \\
\hline & & Information & 1105.7 & 1.7 & 189.7 \\
\hline & \multirow{3}{*}{ Family } & Faces & 1882.5 & 2 & 252.4 \\
\hline & & Logo & 518.2 & 1.3 & 172.7 \\
\hline & & Information & 1122.2 & 2.5 & 170.6 \\
\hline \multirow{7}{*}{$\frac{3}{0}$} & \multirow{3}{*}{ Young person } & Face & 1093.9 & 1.9 & 221.3 \\
\hline & & Logo & 934 & 1.6 & 166.1 \\
\hline & & Information & 2134.8 & 3 & 178.2 \\
\hline & \multirow{4}{*}{ Older person } & Face & 1165.4 & 2.2 & 245.9 \\
\hline & & Logo & 878.2 & 1.3 & 191.8 \\
\hline & & Information & 2977.8 & 3.5 & 234.4 \\
\hline & & Faces & 1087.4 & 1.8 & 190.5 \\
\hline
\end{tabular}




\begin{tabular}{|cllll}
$\begin{array}{c}\text { Grandmother } \\
\text { with } \\
\text { granddaughter }\end{array}$ & Logo & 1137.4 & 1.4 & $\begin{array}{l}187.5 \\
\text { Information }\end{array}$ \\
\hline \multirow{2}{*}{ Family } & Faces & 1890.4 & 2.6 & 221 \\
& Logo & 816.6 & 1.6 & 172.5 \\
& Information & 2079.4 & 2.7 & 136.3 \\
\hline
\end{tabular}

* Revisits refer to the return of a respondent's attention to a specific element of a packet

* Fixation is defined as the time of focusing visual attention on a specific element.

The analysis of these eye-tracking data allows for the verification of the H1 hypothesis. Of all the three specified graphic elements of the packaging: face(s), logo and the basic information: "wheat flour type 500", the most attention drawing is the information about the type of the product. This information received the longest total dwell time, the highest number of revisits and the longest time of a single viewing. Regardless of the packaging colour, as well as the research variant (family, grandmother with a granddaughter, a younger or older face), respondents paid the highest amount of visual attention to the verbal information about the product. This result is hardly surprising, as the identification of verbal information is a more timeconsuming process than absorbing a non-verbal image. However, it should be noted that the indicators of the eye-tracking study for faces have higher values than those for logotypes. Not only the total dwell time, but also the number of revisits and the time of a single fixation have higher values. For the green packaging in the variant: grandmother with granddaughter the total dwell time is nearly three times longer (1552 vs. $591 \mathrm{~ms}$ ). Likewise, the number of revisits is twice as big (2.3 vs. 1.1). All in all, it is worth emphasizing that although a face is not the most significant element on packaging, it does not remain unnoticed. Despite the fact that the H1 hypothesis must be refuted (the basic verbal information drew more visual attention than the faces), the images of people attracted more visual attention of the consumers than the producer's logo.

With a view to verifying the $\mathrm{H} 2$ hypothesis, the eye-tracking research results for two packaging variants: with direct and indirect viewing were compared (table 2).

Table 2. Perception of packaging in terms of the viewing direction of the face.

\begin{tabular}{lllll}
\hline $\begin{array}{l}\text { Viewing } \\
\text { direction }\end{array}$ & $\begin{array}{l}\text { Total dwell } \\
\text { time }\end{array}$ & $\begin{array}{l}\text { Number of } \\
\text { revisits }\end{array}$ & $\begin{array}{l}\text { Number of } \\
\text { fixations }\end{array}$ & Fixation time \\
\hline Direct & 2071.71 & 2.53 & 7.28 & 266.73 \\
Indirect & 1362.82 & 1.84 & 4.50 & 229.25
\end{tabular}

The $\mathrm{H} 2$ hypothesis has been corroborated. The packaging of a product with face viewing directly attracted more visual attention from the respondents. The values of the analysed eye-tracking indicators were higher for this research variant.

The analysis of the survey allows for verifying the H3 hypothesis through the comparison of the declarative choice of a packet (Figure 1). 


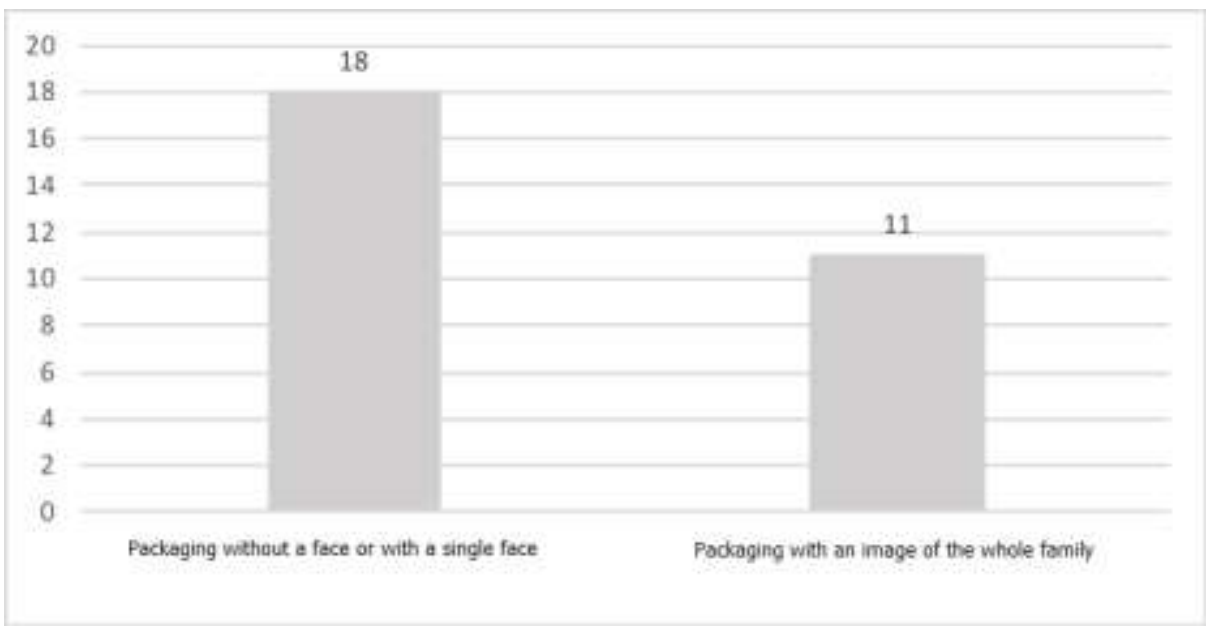

Fig. 1. Preferences for packets in relation to the number of faces

A packet without a face was most frequently selected (by 17 respondents, which accounts for $60 \%$ ). 7 persons would buy a packet with the image of a grandmother and a granddaughter, whereas only two respondents chose the one with a few family members. Nobody declared the purchase of a product with the image of a young woman and only one respondent selected the packet with the image of an older woman. Consumers display a lower tendency to purchase products with the faces of a whole family than those promoted by one person or without any images of people. Therefore, the $\mathrm{H} 3$ hypothesis has been corroborated.

Both the eye-tracking research findings presented in table 1 and the results of the survey allow for a positive verification of the $\mathrm{H} 4$ hypothesis. Among the specified research variants, the elderly consumers displayed higher values of the eye-tracking indexes for packets with the image of an older person than that of a young one. It should be pointed out, however, that in spite of the intensified visual attention devoted to the face of an older person, they are not willing to buy a product with this image. Older consumers prefer packets without any images of persons. As it was mentioned earlier, nearly $60 \%$ of the whole group of respondents chose a packet without a face.

\section{The Effect of a Face on Packaging in Communication with Mature Consumers}

Images of persons are a significant part of marketing messages. Photographs of whole figures or only the faces of male and female models appear in all forms of advertising. They are present in advertisements, promotional materials, billboards, also on packaging and in e-commerce in the broad sense of the term. The faces of persons on packaging play a significant role in shaping the behaviours and the attitudes of consumers in relation to brands and products. A human face, as an element well-known to the recipient, makes the product more accessible and less "alien" [18]. However, a 
face should display certain qualities, in order to attract the attention of a target consumer. Research findings [2] confirmed differences in consumers' responses to a face image in relation to the physical attractiveness of the presented person. The attractiveness of the person shown in a marketing message draws attention and arouses interest, but sometimes also causes some discomfort resulting from the recipient's low assessment of their own appearance. Therefore, the authors formulated the following hypothesis:

H1: Of all the elements of packaging, a face attracts the highest visual attention of elderly consumers.

What is more, a consumer's interest in a product depends on the viewing direction of the model. From the point of view of the effectiveness of marketing communication, it is essential to properly design the viewing direction - direct or indirect. Direct viewing means that the model's eyes are looking straight forward (in the consumer's direction); whereas averted viewing means that the model's eyes are looking to the side, or simply not in the consumer's direction. Most frequently the model is looking at a brand or a product, much less often in an unspecified direction. Research findings into this issue are ambiguous. The research conducted by Wang, Wedel, Huang and Liu [17] on over 200 websites indicated that direct and indirect viewing occur equally frequently. Others claim that direct viewing results in a higher concentration on the middle part of the model's face, delaying the identification of peripheral objects [14]. On the other hand, the averted viewing may shift the consumer's sight and attention, leading to a quicker identification of objects located outside the model's face. Sajjacholapunt and Ball [13] proved that placing a face looking in the direction of a brand or a product raises the interest in the product and facilitates remembering information which allows for formulating the following hypothesis:

H2: With respect to older consumers, packaging with directly viewing faces attract more visual attention than those with indirectly viewing faces.

Belonging to the older-age segment is defined in terms of three categories - the nominal, biological and cognitive age [7]. The nominal age is related to the date of birth, which allows for a further division of seniors. Notes on packaging: $40+, 50+$, or $60+$, which are sometimes referred to as stigmatising a consumer, are used on many cosmetic products dedicated to older persons. Nevertheless, there is no certainty that this is an effective marketing impulse in communication with older consumers. The biological age defines the condition of the organism, resulting from the earlier life style, illnesses and injuries. The concept of the cognitive age refers to the thoughts and feelings of an individual person in relation to the subjective perception of their own age and condition. The cognitive evaluation of age is individually formed and changes as a result of a disease, retirement, or losing a partner. It is the cognitive age that determines life satisfaction and its discrepancy with the chronological age are strongly related to self-esteem [15]. Mathus et al. [9] claim that the use of cognitive age in the context of senior consumers allows for a better understanding of the way in which age affects their purchasing behaviour.

Life satisfaction is an ambiguous term which refers not only to happiness or wellbeing, but also to the quality of life. Life satisfaction is defined as the overall assessment of one's own achievements and life conditions, which changes in time [3]. Life 
satisfaction usually refers to the specific spheres of life - family life, professional activity, health and financial situation. Professional inactivity, deterioration of health, reduction of income and the loss of social relations experienced at an older age make it necessary to satisfy one's needs according to a specific hierarchy. Therefore, it can be concluded that older consumers feel diminished life satisfaction [19]. A significant aspect of life quality, determining life satisfaction, are family relations and satisfaction with family and children. It appears, though, that with the growing age this type of satisfaction is decreasing. The age group most satisfied with their children are young parents (aged 25 - 44). Among people aged 55 and more diminished satisfaction with children is observed [20]. Older parents are not as satisfied with their children as the younger ones, which makes the image of a family (seniors with children and grandchildren), as well as young faces on packaging less attractive to them. This leads us to the formulation of the following hypothesis:

H3: The declining life satisfaction of elderly consumers leads to a decrease in the attractiveness of a family image, which, in turn, results in their lower preference for products with images of the whole family on the packaging.

On the basis of research, Berg, Söderlund i Lindström [1] assumed that faces expressing positive emotions build consumers' positive attitudes towards the products, by way of the process of infecting with emotions (imitation). Moreover, there is empirical evidence [4] that older people pay more attention to and remember better positive faces than negative ones. It can be assumed that the common presence of the smiling faces in marketing messages will emphasise the reality of the respondents' situation and at the same time will allow for verifying the viewing direction and the model's age, as well as the number of faces displayed on packages in the process of an intentional purchase. The face's age affects the consumer's cognitive effort. Older persons' faces usually require more time for identification than younger ones, due to their complexion and wrinkles. That is why it is assumed that it is easier to control the expression of younger faces. Older persons appreciate the attractiveness of young faces; however, feeling the deficit of this quality in themselves, will rather purchase products promoted by their peers. As a result, the following hypothesis was formulated:

H4: For senior consumers packaging with an image of an older face draws their visual attention but is not the subject of an intentional purchase.

*The full family is understood as a grandmother with a granddaughter and a few other family members.

\section{Conclusions}

Results of the research show that presumably the face effect on a product packaging does not play as significant role in reference to older consumers as it was expected. Only a few of the respondents noticed faces. What is more, they preferred packets without a face image or with only one face. A question remains whether the lack of the strong effect of a face would be present on a larger scale and in the more realistic conditions of shopping, or with reference to another category of products. 
The article contributes to determining the direction of the impact made on the older consumers' preferences by such packaging elements like faces of people promoting a product. The main limitation of our study is a relatively low number of participants. A bigger sample could have resulted in more reliable results. The research was conducted on a very small group of respondents, all of whom being professionally active. Moreover, their tasks were related to the assessment of one product displayed on a screen. Creating more realistic conditions - more options to choose from, or a time limitation, could induce the respondents to use System I in their decision-making process, which would entail quicker and more automatic choices, with the exclusion of the conscious processing of information. Additionally, the respondents' professional activity and their life satisfaction, probably accompanied by emotional stability, could contribute to their omission of faces in the assessment of the presented packages and affect their purchase decisions.

Another factor which may have played a role in this research was the fatigue effect - each respondent evaluated 10 packages, which could result in tiredness and lower concentration. Another limitation of the research was the fact that only persons with good eyesight were admitted (persons with a sight defect stronger than $+/-2$ dioptres, wearing contact lenses, with glaucoma, a cataract or with an eyeball implant were excluded), which may have limited the adequacy of the obtained results in relation to the group of older consumers.

\section{References}

1. Berg, H., Söderlund, M., Lindström, A.: Spreading joy: examining the effects of smiling models on consumer joy and attitudes. Journal of Consumer Marketing, 32(6), 459-469 (2015). DOI:10.1108/JCM-03-2015-1356.

2. Bower, A. B., Landreth, S.: Is Beauty Best? Highly Versus Normally Attractive Models in Advertising. Journal of Advertising, 30(1), 1-12 (2001).

3. Diener, E., Emmons, R. A., Larsen, R. J., Griffin, S.: The Satisfaction with Life Scale. Journal of Personality Assessment, 49(1), 71 (1985).

4. Ebner, N. C., He, Y., Johnson, M. K.: Age and emotion affect how we look at a face: Visual scan patterns differ for own-age versus other-age emotional faces. Cognition \& Emotion, 25(6), 983-997 (2011). DOI: 10.1080/02699931.2010.540817

5. Ekman, P., Friesen, W.V.: Constants across cultures in the face and emotion, Journal of Personality and Social Psychology ,17 (2), 124-129 (1971).

6. Jerzyk, E.: Możliwości i ograniczenia wykorzystania eye-trackingu w badaniach starszych konsumentów, Marketing i Zarządzanie, 2, s. 133-140 (2017).

7. Jerzyk, E.: Wymagania starszych konsumentów wobec opakowań jednostkowych, Marketing i Rynek, 6, s. 318-329 CD (2014).

8. Kahneman, D.: Pułapki myślenia. O myśleniu szybkim i wolnym. Poznań: Media Rodzina (2012).

9. Mathur, A., Ong, F., Fatt, C., Rakrachakarn, P., Moschis, G.: Beyond cognitive age: developing a multitheoretical measure of age and its assessment. Journal of Marketing Analytics, 5(1), 31-43 (2017) DOI:10.1057/s41270-017-0011-9

10. Mccracken, G.: Who Is the Celebrity Endorser? Cultural Foundations of the Endorsement Process. Journal of Consumer Research, 16(3), 310-321 (1989). 
11. Olejniczak, T.: Przemiany segmentu konsumentów seniorów w Polsce, „Marketing i rynek”, luty, s.

196-210,

http://www.marketingirynek.pl/files/1276809751/file/ibrkk_cd_mir2_2005.pdf (2015)

12. Pieters, R., Warlop, L.: Visual attention during brand choice: The impact of time pressure and task motivation. International Journal of Research In Marketing, 16(1), 1-16 (1999).

13. Sajjacholapunt, P., Ball, L. J.: The influence of banner advertisements on attention and memory: human faces with averted gaze can enhance advertising effectiveness. Frontiers in Psychology, $\quad 5, \quad 166 . \quad$ http://doi.org/10.3389/fpsyg.2014.00166, https://www.ncbi.nlm.nih.gov/pmc/articles/PMC3941030/, last accessed: 21.03.2018.

14. Senju, A., Hasegawa, T.: Direct gaze captures visuospatial attention, VISUAL COGNITION, 12 (1), 127-144, https://pdfs.semanticscholar.org/790e/6f93164f92eb7fdc7585e1dfd912a60a0b02.pdf, last accessed: 21.03.2018.

15. Sirgy, M. J.: Self-Concept in Consumer Behavior: A Critical Review. Journal of Consumer Research, 9(3), 287-300 (1982).

16. Wang, Q., Wedel, M., Huang, L. Liu, X.: Effects of model eye gaze direction on consumer visual processing: Evidence from China and America. Information \& Management (2017), https://doi.org/10.1016/j.im.2017.12.003 (2016).

17. Wang, Q., Yang, Y., Wang, Q., Ma, Q.: The effect of human image in B2C website design: an eye-tracking study. "Enterprise Information Systems", No. 8(5) (2014).

18. Wiśniewska, M., A., Liczmańska, K.: Wykorzystanie postaci jako instrumentu perswazji w reklamie, Roczniki Ekonomiczne Kujawsko - Pomorskiej Szkoły Wyższej w Bydgoszczy, nr 4, 133-149 (2011).

19. Włodarczyk-Śpiewak, K.: Aspekty jakości życia a poziom satysfakcji życiowej Polaków, Nierówności społeczne a wzrost gospodarczy, nr 9, Problemy globalizacji i regionalizacji, cz.2, 513-526 (2006).

20. Zadowolenie $\mathrm{z}$ życia, Komunikat $\mathrm{z}$ badań, CBOS, $\mathrm{nr}$ 3/2017, http://www.cbos.pl/SPISKOM.POL/2017/K_003_17.PDF (2017). 